\title{
Simple but Dominant: How to Re-shine Depeche Mode on Album Covers After 80's
}

\author{
Cinla Sekera
}

\begin{abstract}
The aim of this paper is to analyze the album covers of English band Depeche Mode after 80's according to the principles of graphic design. Established in 1980, the musical style of the band was turned from synth-pop to new wave, from new wave to electronic, dance, and alternative-rock in decades, but their message stayed as it was: A non-hypocritical, humanist, and decent manner against what is wrong and in love sincerely. As a graphic design product, album covers are pre-print design solutions of two dimensional surfaces. Graphic design, as a design field, has its own elements and principles. Visual elements and typography are the two components which should unite with the help of the six main principles which are: unity/harmony; balance; hierarchy; scale/proportion; dominance/emphasis; and similarity and contrast. All album covers of Depeche Mode after 80's were designed in a simple but dominant way in order to form a unique style. On every album cover, there are huge color, size, tone, and location contrasts which concluded in simple domination; domination of a non-hypocritical, humanist, and decent manner against what is wrong and in love sincerely.
\end{abstract}

Keywords

Graphic design, album cover, design principles, dominance, Depeche Mode

Design is the formal and functional features determination process, made before the production of a product. Among many other production items, printed 2D materials are the subjects which graphic design is dealing with. Graphic designer organizes the 2D surfaces with typography and visuals like photographs or illustrations (Shaughnessy 2005: 18). As graphic design products, album covers are the packages of music at the same time (Gomez-Palacio and Wit 2011: 251). These packages both protect and visualize musical expression. The genre of music and the expression of the musicians shows itself on these covers by using special visuals and typographic combinations which are the main components of graphic design.

With the help of an album cover, the music reflects itself visually. The main visual elements of graphic design are line, shape, color, value, texture, and space. For a successful visualization, some graphic design principles should have been considered by the designers. The six main graphic design principles are: unity/harmony; balance; hierarchy; scale/proportion; dominance/emphasis; and similarity and contrast (Dabner, Calvert, and Casey 2012: 34-58). This means that in the organization of the visual elements, the graphic designer should take the graphic design principles into consideration. The aim of this paper is to analyze the album covers as

aDokuz Eylul University, Turkey

\section{Correspondent Author:}

Cinla Seker, Ugur Mumcu Caddesi 135 Sokak No. 5 Buca 35150 Izmir, Turkey

E-mail: cinla.seker@deu.edu.tr 
form and content of the English band Depeche Mode during and after 80 's according to the principles of graphic design.

Established in 1980, the musical style of the band Depeche Mode was turned from synth-pop to new wave, from new wave to electronic, dance, and alternative-rock in decades, but their message stayed as it was: a non-hypocritical, humanist, and decent manner against what is wrong and in love sincerely. Depeche Mode is still an active band and has been 31 times nominated and 10 times won the highly prestigious worldwide prizes. It is the most popular electronic band the world has ever known and it is in the list of the 50 bands that changed the world. As seen in Figure 1 from left to right, Depeche Mode are Alan Wilder (1959), Martin L. Gore (1961), Andy Fletcher (1961), and Dave Gahan (1962) with slight differences (Miller 2009: 7-9; Bernhardt 2007: $3-5)$.

\section{MUSICAL GENRES RELATED TO DEPECHE MODE}

Music can be defined as an art form which is vocal or instrumental sounds (or both) combined in such a way as to produce beauty of form, harmony, and expression of emotion (Steyn 2012: 10). Genres and subgenres of popular music named after the musical techniques, the style, the cultural context, and the content and the spirit of the themes and sometimes, simply features of musical instruments or geography used (Holt 2007: 4-9). The musical style of Depeche Mode has changed from synth-pop to new wave, from new wave to electronic, dance, and alternative-rock in decades from 1980s to nowadays.

While electronic music was defined as music made by electronic musical instruments and technology (Emerson 2007: 90), synth-pop was also known as electro-pop or techno-pop used synthesizer as a dominant instrument (Kosmicki 2009: 236). Modular synthesizer was designed in 1960, generating electric signals that are converted to sound through instrument amplifiers and loudspeakers or headphones (T. B. Holmes and T. Holmes 2002: 5-7). Industrial music, which is also a genre of experimental/electronic music that draws on transgressive and provocative themes. It is the most abrasive and aggressive fusion of rock and electronic music; initially a blend of avant-garde electronics experiments and punk provocation (Reed 2013: 317).

Rock music is one of the many genres which is under the effect of the usage of electronic musical instruments, and a subgenre called electronic rock, synth-rock, electro-rock, techno-rock, or digital rock (Waksman 2001: 238). Another musical genre of popular rock was created 1975-1985 called the new wave. The sound of the genre was rooted in smooth blues and rock \& roll but was differed with its twitchy, agitated feel, choppy rhythm guitars, and fast tempos. New wave has resemblance to first-wave punk but not punk rock with touches of electronic, experimental, mod, disco, and pop (Ray 2013: 210; Bernhardt 2007: 7).

Simply punk or punk rock is also rock music developed during 1974-1976 as a rejection to the mainstream 1970s rock. It is typical with its short or fast-paced songs, with hard-edge melodies and singing styles, stripping down instrumentation, and is often political, and having anti-establishment lyrics which are standing in opposition to the conventional social, political, and economic principles of the society. After punk movement of 1970s, post-punk occurred as a combined type of rock music. Post-punk musicians were innovators and experimentalists mixed a group of genres, like electronic music, black dance styles, and the avant-garde with rock music. They have not hesitated trying new and interesting recording and production technology and techniques (Crossley 2015: 49).

In the early 1980s besides punk, disco also died and as a post-disco genre, dance-rock occurred connected with electronic and pop rock with fewer 


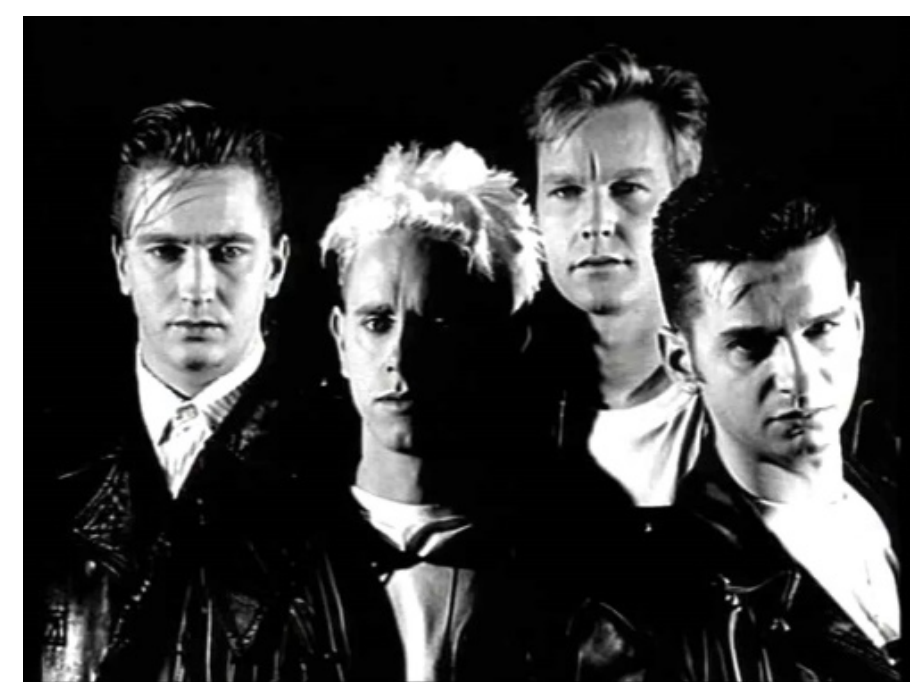

Figure 1. Depeche Mode (1990s). Source: Http://classicalbumsundays.com/album-of-the-month-depechemode-violator.

rhythm and blues influences (Haden-Guest 2015: 149). Alternative rock, also called alternative music, alt-rock or alternative, is a genre of rock music that emerged from the 1980s' independent music underground and became widely popular in the 1990s and 2000s. The word alternative refers to the genre's distinction from mainstream rock music. The term originally refers to a generation of musicians unified by their collective debt to either the musical style or simply the independent, do-it-yourself culture of punk rock, which in the late 1970s laid the groundwork for alternative music. Term has been used as to refer all music from underground rock artists that receives mainstream recognition, or for any music, whether rock or not, that is seen to be descended from punk rock, punk itself, as well as new wave, and post-punk (The Wikipedians 2010: 2; Star 2009: 10).

So from 1980 until 2010s, Depeche Mode had combined many different genres and styles in their own way and created a unique music to themselves. Like every human in their journey of life, on the journey of musical creation and expression, they had tried different paths to find themselves. In this artistic journey, visual designs also helped them to communicate, meet their audience and create an audio-visual history, as a conclusion, helping them with their self-actualization. The next chapter put forth the visual reflections of this musical journey by analyzing the formal and contextual features of the studio album covers of Depeche Mode.

\section{FORM-CONTEXT ANALYSIS OF DEPECHE MODE ALBUM COVERS}

\section{Musical Periods of Depeche Mode}

1980s. After establishing in 1980, the group released four studio albums every year until 1984 . While the first two of the quartet both Speak \& Spell released in 1981, and A Broken Frame released in 1982 were labelled as synth-pop as musical genre. While the third album Construction Time Again released in 1983 was labelled as industrial music, the last of the quartet Some Great Reward released in 1984 was labelled as pop, industrial, and electronic music. Like their musical styles, the design attitudes of the four album covers are quite similar.

On the all of four album covers, as seen in Figure 2 , realist photography is used in the surrealist context. This means real life object and environments can be 

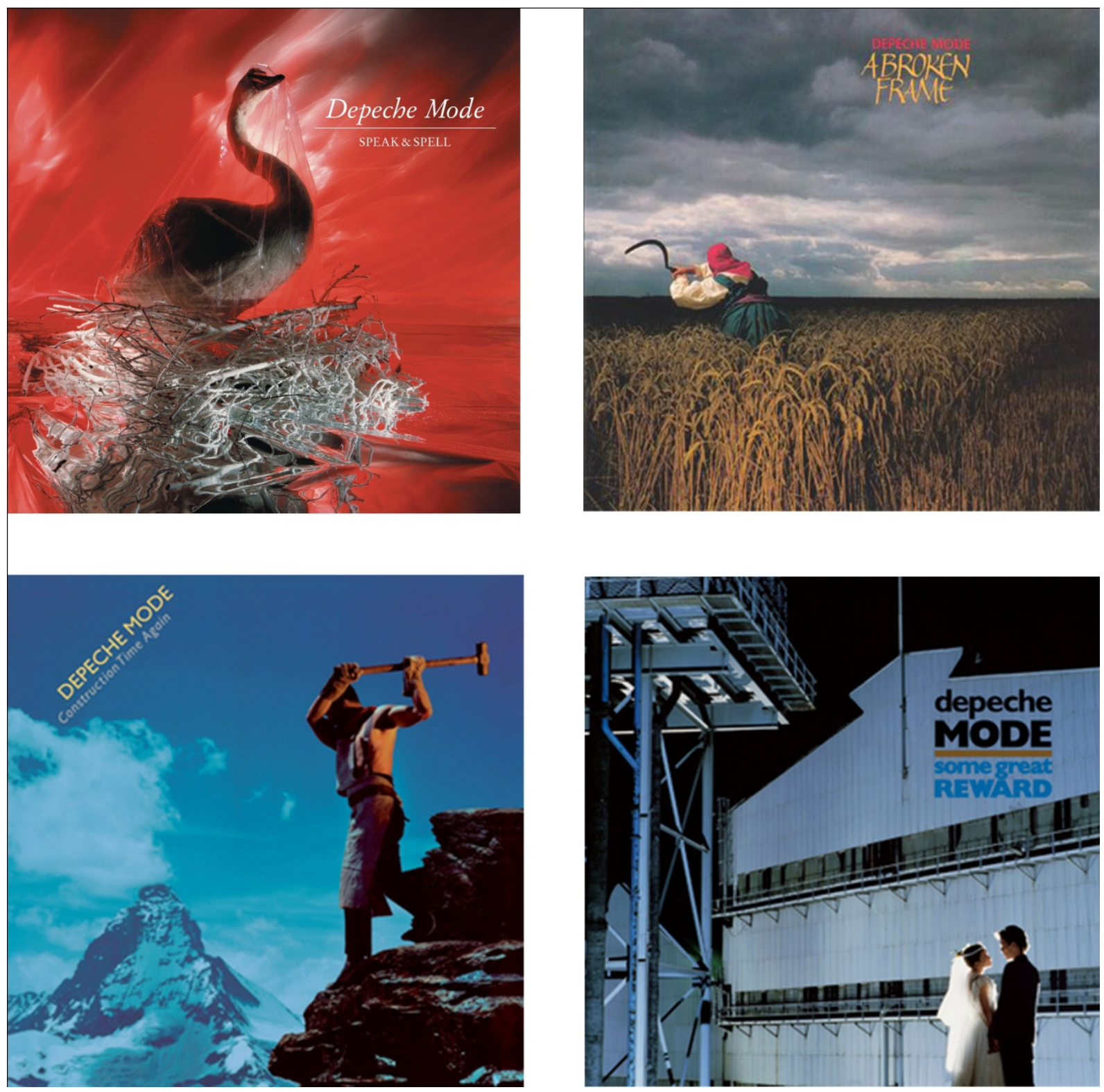

Figure 2. 1981-1984 Album Covers. Source: The author's collection.

seen as real but in unreal situation or environments. At first sight, it is easy to see that the color scheme used is getting colder and less saturated cover by cover. The brightest of the four is the oldest one: Speak \& Spell. On the cover of the album, a real white swan is seen in a red sea swimming in front of a red sky. It is in a plastic transparent bag in which it cannot breathe, so it cannot be alive. The grey branches the swan sitting on look like they belong to a different world because of their color. The monochrome color scheme is used in red with millions of tones. While bright red is the main color, white, black, and millions of tones between are neutrals. The neutrals are suitable for every color scheme and they leave the leading role to the owner, the red.

If looking carefully, it is seen that the horizon of 
the photograph is laying just under the golden section, which creates two unequal but aesthetic parts. Golden section is a divine proportion rooted in nature which is unequal but accepted as aesthetically harmonious. Because the swan and the branches are placed a little left from the center of the cover, so the left half of the cover is overfilled. In order to balance this fullness, the swan turns its head right, and the black and white tones coming from top and bottom toward center vanish toward the middle of the cover. Like an oil painting, the sky and the sea have brush strokes as texture. The branches and the swan are textured by their nature. Only the plastic transparent bag which covers the swan and the white typography are contrasting with all of these textures with their flat surfaces.

Human eye is used to see things in balance in its environment, because it lives under the effect of gravity of the earth, and as a conclusion, it expects to see balanced elements in everywhere. The name of the band Depeche Mode together with the name of the album is placed on top right, in order to balance the other elements asymmetrically. A typeface with tiny serifs but curving finishes is used in order to suit the grace of the white swan. White typographic elements are contrasting as tone and as size with the photograph all over the surface. The name of the band is placed above the name of the album. They are aligned, centrally, and separated with a thin line, which is graceful too. Because the band was not famous yet, the name of the band was introduced in larger sizes.

Like the cover of Speak \& Spell Album, the other three that belong to these period are designed in a similar way. All three have a photograph, which focuses up to the sky as a background. All three photographs have surrealist context because of their themes and illumination. On the cover of A Broken Frame Album, there is a harvest scene illuminated dramatically like in Baroque painting. The farmer with his outfit and sickle belongs to pre-modern times. With these characteristics, this photograph is contrasting with the musical style of the album, which is produced with the latest production techniques. On the cover of the Constructing Time Again Album, there is a proletarian seminude figure hammering while climbing down in front of snowy rocky peaks and a semi cloudy cold looking sky. On the cover of the last album named Some Great Reward, there is a newly married couple dressed as bride and groom, which are in love seen in way of looking to each other. The couple is seen standing in front of a factory-like huge building at night which is unusual. All of the photographs, there is a light coming from unnatural sources and directions to illuminate the figures.

On all of the three covers, photography dominates because of the small sizes of the typographic elements, which is contrasting with the full size of the photographs. On every cover, typographic elements are placed somewhere in order to balance other elements asymmetrically. On every cover, the color of the typographic elements suits as hue but contrasts as value: light on dark or dark on light. On every cover, the name of the band and the name of the album are placed close to each other and perceived and designed as a group.

Depeche Mode released another studio album named Black Celebration in 1986. It was labelled as industrial and synth-pop. The 1987 released album after one year, named Music for the Masses was labelled as electronic, synth-pop, and post-punk. After two years from 1984 to 1986, new features were added to the music of Depeche Mode and the cover design attitude had changed. The surface of the cover which was every time a square of 11 centimeters began to be divided into sections. The photographs are getting smaller in size and a calm space occurrs around. All the elements on the cover are aligned in center vertically. On the cover of the Black Celebration, there is a photograph which is not clear, consisting of overlapping scenes printed on each other to create a surrealist image. A grey sky scraper with some colored windows and black ribbons with some 

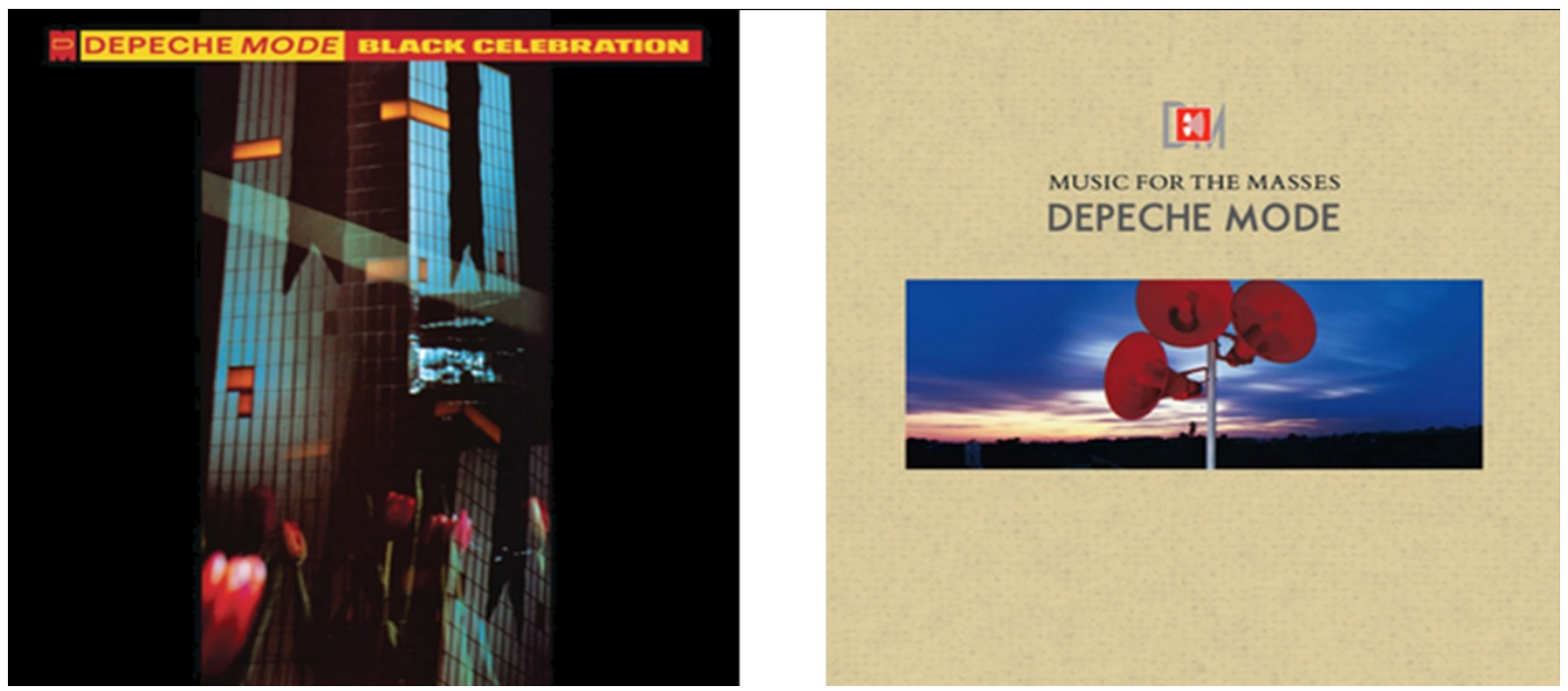

Figure 3. 1986-1987 Album Covers. Source: The author's collection.

flowers in front, form an image of black celebration. The black background, some colored windows, and flowers make the photography perceived as closer. Typography is designed as a logotype with an emblem colored in bright warm colors and the small size of the lettering is contrasting with the rest of the cover. With the big sizes of the flowers in front, the designer balances the colorful typography which is on top.

The modern sans-serif fonts are used on both of the covers suiting the plain grounds behind, as seen in Figure 3. Again on the cover of the Music for the Masses Album, typographic elements are organized as a logotype with an emblem. An extraordinary surrealist photograph is placed in the middle of the cover. In the middle of the photograph, there is a pole with three red megaphones on it. It is an extraordinary scene. With their proportions and locations, the photograph and the typographic elements balance each other. The asymmetry is caused by the three megaphones in the middle, balanced diagonally with the bright sunlight coming from left up. The cream colored background comes closer and is perceived as a frame in front of the photograph because of the deep going effect of the photography.
Texture as design element is also contrasting on the both of the covers with the non-textured areas. While on the first cover Black Celebration, windows of a skyscraper are contrasting with plain black background, on Music for the Masses, textured cream background is contrasting with the plain areas of photography.

1990s. Another Depeche Mode studio album named Violator was released in 1990 labelled as pop, rock, and electronic. After Violator, in 1993 Songs of Faith and Devotion was released and labelled as electronic rock, alternative dance, industrial rock, and new wave. The design attitudes of the two album covers are similar, despite at first sight, they are looking different. As seen in Figure 4, the visuals used on the covers are not photographs anymore. They are rough-edged and multi-piece illustrations with three tones only, which are black, white, and powerful dark colors like red or purple. There are black backgrounds and freehand typography designed in a unique way. Freehand typography is handwritings made for these covers only and used only for once. After pure rock effecting their music, the designs of the covers are turned into something rough, full of irregular shapes 


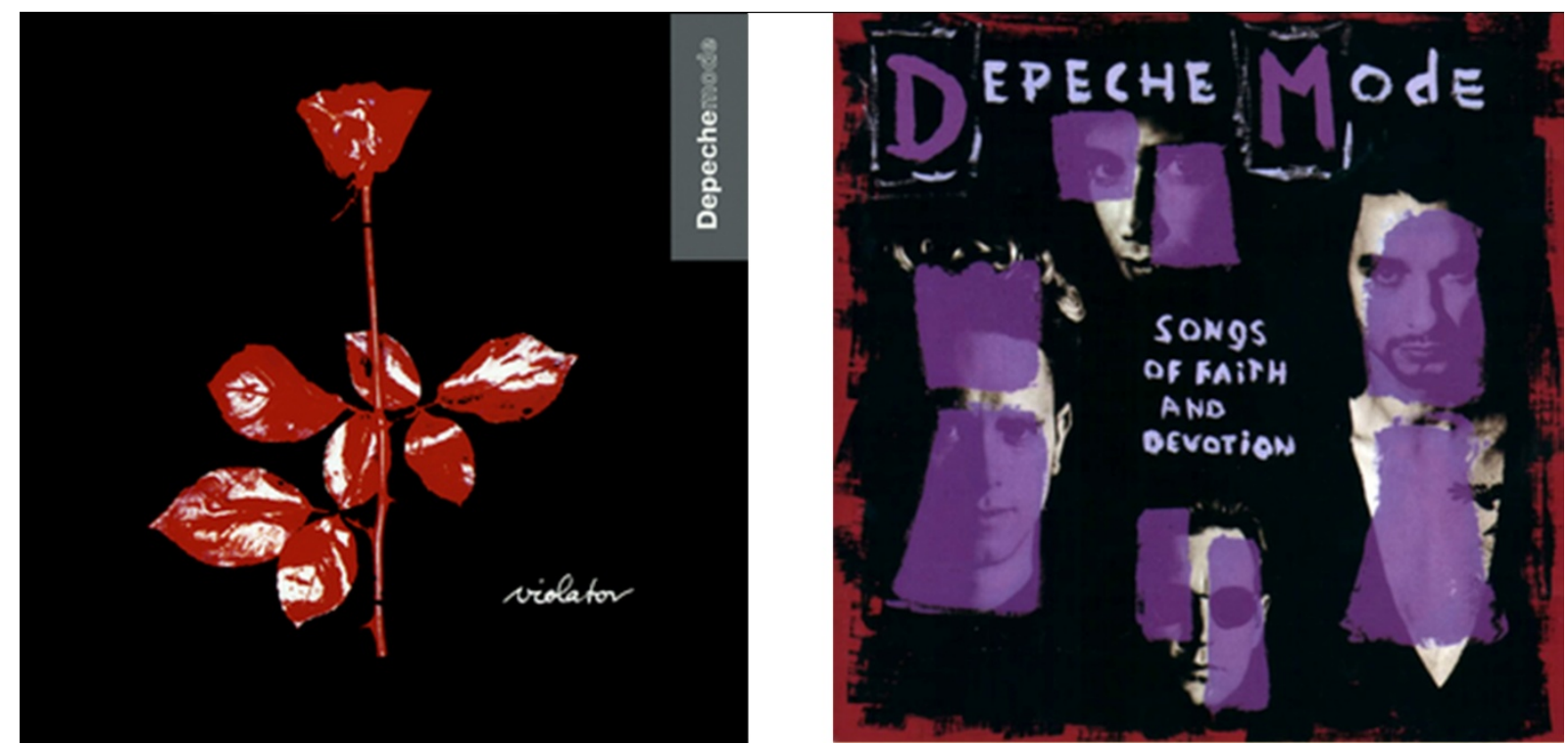

Figure 4. 1990-1993 Album Covers. Source: The author's collection.
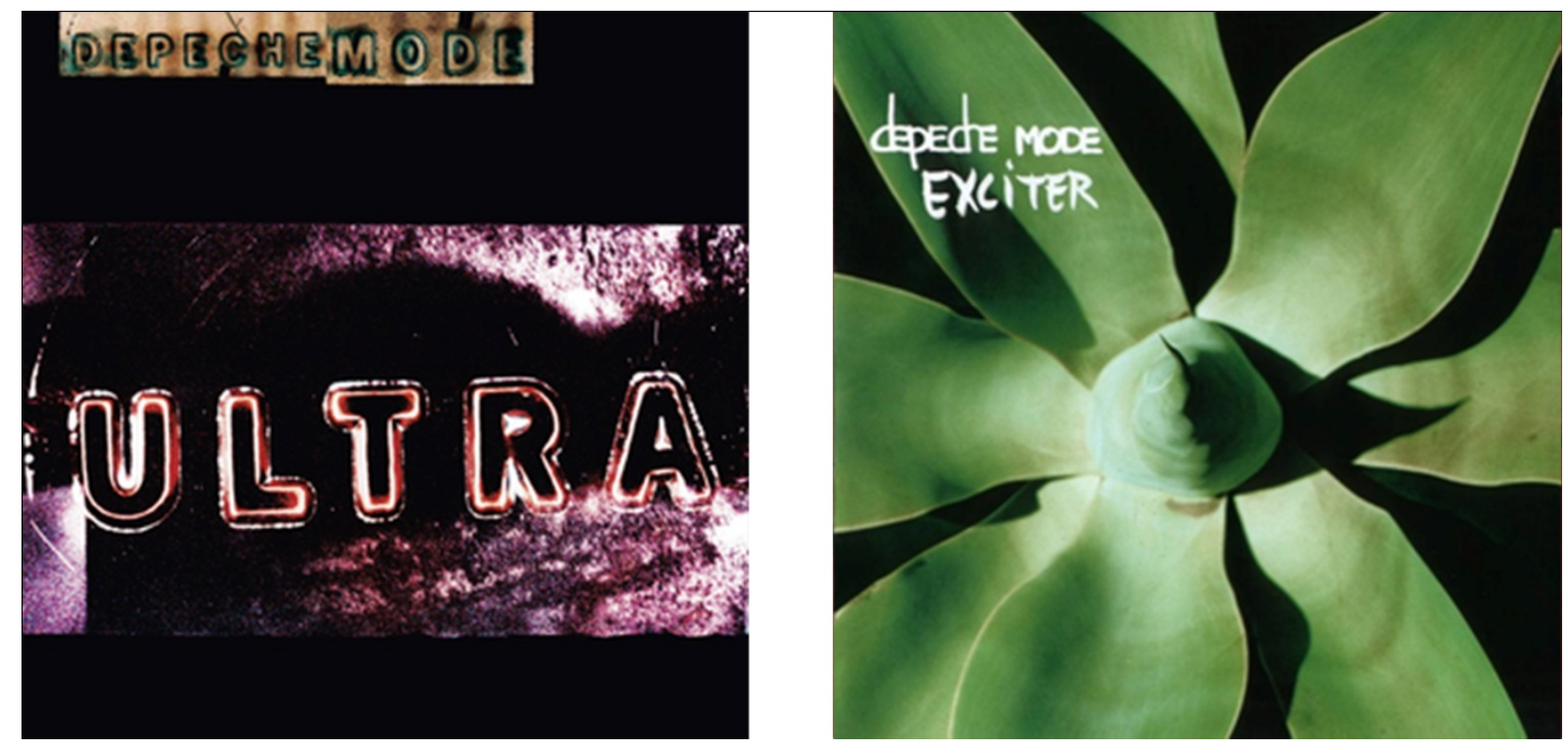

Figure 5. 1997-2001 Album Covers. Source: The author's collection.

with reduced number of tones and colors. But this time, the color itself dominates the cover with its power because of its singularity. The design attitude of balancing asymmetrical elements with others has not changed.

In 1997, released studio album of the band named Ultra was labelled as alternative dance, electronic, industrial, and alternative rock. On the other hand, in 2001, released studio album Exciter combined all characteristics of Depeche Mode with soul music, which combined the elements of African-American gospel music, rhythm, and blues and jazz. For Depeche Mode, being an alternative music band, is reflected by visual effects on the cover of the album Ultra. 
Undefinable textures of over-blurred image are seen on the cover in a combination with typographic elements. With the invention of digital typography and photography, a new design approach occurs. The old, torn, and worn looking image created on the cover's visual and verbal elements has a resemblance of the situation of the soul of Depeche Mode, which is reflected with their music and lyrics. Texture dominates the cover as an element of design with a small amount flat grounds left. A form and content relation can be seen on the size of the name of the album which covers almost all the surface. In order to make the composition more dynamic, the name of the band is placed top left in little sizes. Neutral color scheme is used with a little bit in three colors purple, red, and green, which are complementary.

On the cover of the album Exciter, texture is the dominant element again, but this time in fine-grained. In between the leaves, there are flat black shadows helping to increase the effect of texture. The reddish green color of the plant is all over and the centralized composition takes the attention. Dynamism is created with the top left placement of the typographic elements again. Freehand typography has characteristic cambers like the leaves have. White typographic elements tone as color suits with the light areas around the center of the plant. Size contrast is used as a feature to take attention on both covers. While in Ultra, huge typography takes the attention, in Exciter, huge plant with its oddity and size take the attention, as seen in Figure 5. On the cover of Exciter, both shapes and textures smoothen like the smoothened musical style of the album. Rebellious hard guitar riffs leave some of its place to smooth soul's companionship combined the style of the band.

New millennium. While in 2005, released studio album of Depeche Mode Playing the Angel was labelled as synth-pop, alternative dance, industrial, and alternative rock, the Sounds of the Universe album released in 2009 was labelled as synth-pop and electronic rock. On both covers, as seen in Figure 6, graphic design elements - line and shape dominate the covers, which means both covers' designs turn their faces to the basic elements of graphic design. On the cover of the Playing the Angel, black figures are seen on a multi-piece background formed with different tones of grey. The names of the band and the album are drew freehand on both sides and a creature made of feather standing in the middle. While different sizes and organization among the typographic elements balance the two halves, the location and the shapes of the pieces on the background balance the asymmetry. On this cover, texture is again a dominant element. The multi-piece background's giant grains are contrasting with the thinness of the feathers of the creature.

On the cover of the Sounds of the Universe, an image is created resembling a message sending world with the help of thick lines in different colors. Lines with different directions on a black circle are contrasting with the grey flat surface. Like many covers, the initials of the name of the band are emphasized with the thick lines. While the name of the band written with a sans-serif modern font lays on top justified, the name of the album lays down in the middle with lower cases of the same font but in white. The two groups are balancing each other with their sizes and locations.

Last album of Depeche Mode was Delta Machine released in 2013, which was labelled as electro-pop, industrial, and synth-rock. A multi-piece factory is seen in monochrome dark red in Figure 7. What a coincidence red was the color of the first Depeche Mode studio album released in 1981. The photograph consists of lots of geometric shapes and a few lines in different tones. Dark red color lightens while going up step by step. A huge logotype is designed by using freehand shapes, letters, and a line in black. A little change in size and the location between words indicates which is the name of the band and which is the album. Placing the logotype's line in the center, balancing the dark red areas which is under the line 


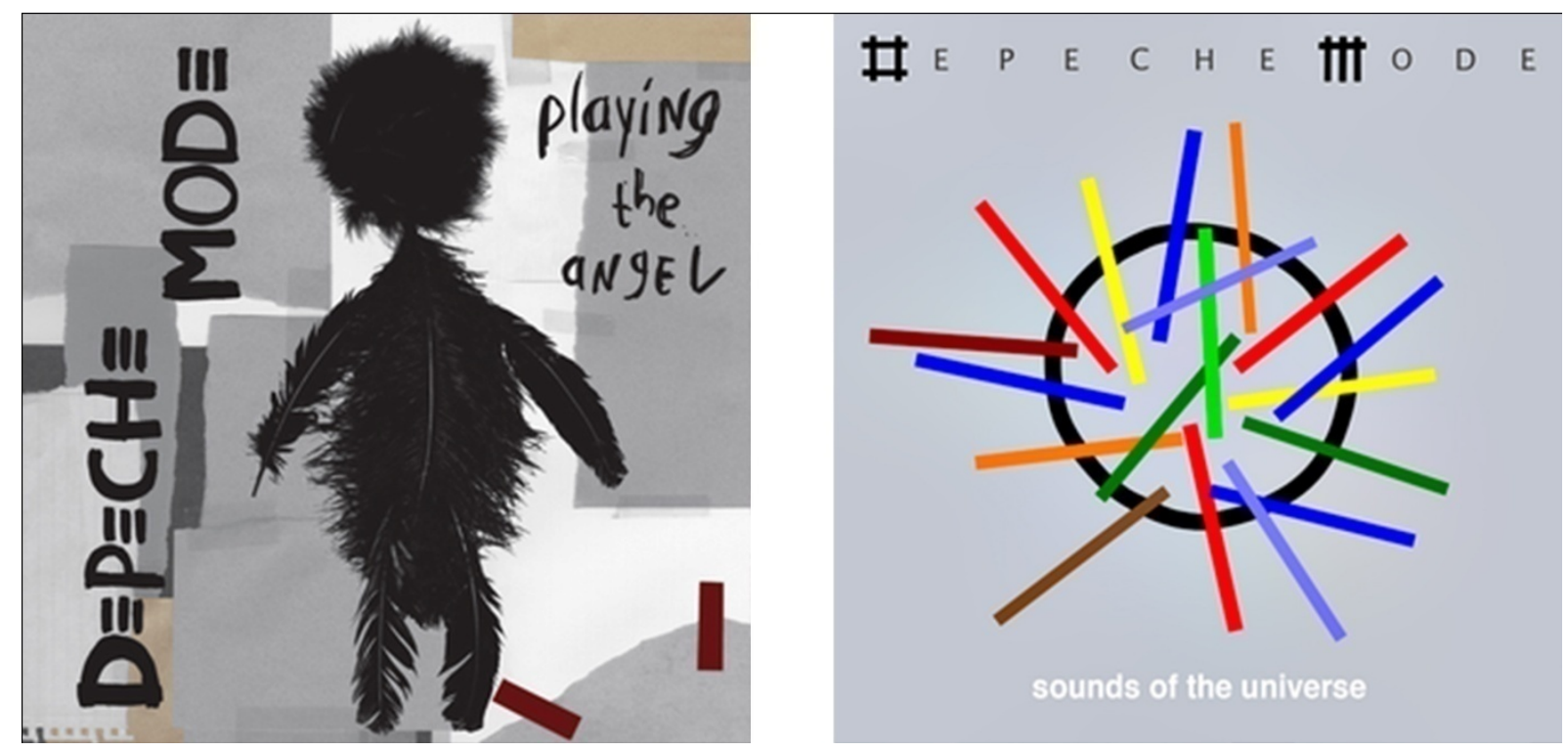

Figure 6. 2005-2009 Album Covers. Source: The author's collection.

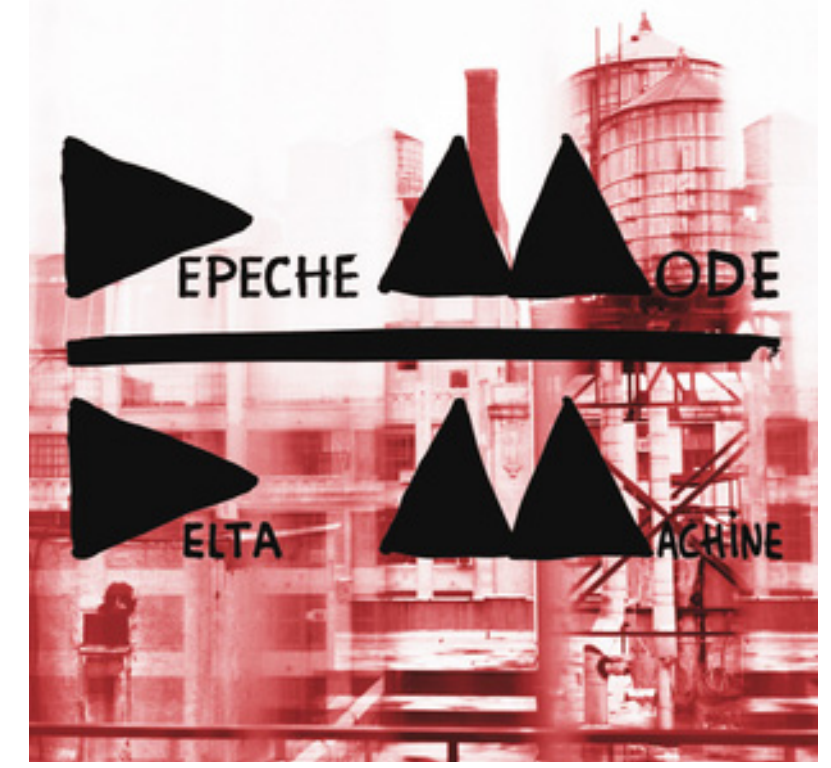

Figure 7. Delta Machine (2013) Album Cover. Source: The author's collection.

with the huge name of the band which is over. The black triangles are used to create the two Ds, balancing the two cylinder tanks which are rising. The two triangles created $\mathrm{M}$, suiting the cone roofs of the tanks. The thick black line in the middle of the logotype suits with the dark red horizontal thick lines down.

\section{CONCLUSIONS}

During 80 s, on every album cover of Depeche Mode, there is a photography as a background, which looks real but they are contextually surreal. All six photographs focus above the horizon and have the illusion of depth. Photographs which are dominating the covers got smaller in size on cover by cover. 
Figure-ground differentiation began to occur on covers. Any image of the band or band members is used as photograph. The warm color schemes are getting colder and colder. Fonts using in typography have tiny or no serifs but they are classic. The classic fonts leave its place in modern sans-serif fonts. Asymmetrically, balanced, and diagonal compositions are turned into symmetric ones.

During 90s, no photography was used on the covers, only illustrations and shapes were used as visuals, except Exciter, on which an unusual framed photography of an unusual plant was used as an image. On these illustrations, there was always one powerful color dominating neutral colors, which were brown, grey, black, and white. Freestyle typography made freehand was used in order to create an artistic and unique look. Figure and ground separated, figure-ground differentiation occurred. Typography, color, or texture dominated the covers. There was always a black background. Asymmetric composition was turned into symmetric, centered, or justified.

With the new millennium, no photography or highly effected photography was used on the covers. Figure-ground differentiation continued. While some elements were perceived as figure, some perceived as ground and grey, fragmented or colored backgrounds they had. Shapes dominated the cover as figure or as typography made by shapes or thick lines. On every cover, neutral color scheme was used in a combination with some mature colors and all the covers had centered or justified compositions. Freestyle typography continued as mixture of shapes, lines, or typed writings.

When looking in general, the album cover design attitudes are related with the musical attitudes. Album cover design attitudes are changing with the musical changes. Album cover design attitudes are every time based on the six main design principles. With 90's, there is a significant and ongoing musical change followed by the changing design attitudes, which are: Realist imagery left its place into fragmented surrealist imagery toward new millennium. Real life photography left its place to the elements of design like line, shape, and texture. Real life colors left its place into neutrals dominating with one brilliant. Regular typographic style left its place to freestyle typography based on lines and shapes. Asymmetrical balance left its place to symmetrically balanced, centered, or justified composition.

\section{References}

Bernhardt, T. 2007. Depeche Mode: A Band, Its Music, and the Cult. Norderstedt: Grin Verlag.

Crossley, N. 2015. Networks of Sound, Style, and Subversion: The Punk and Post-Punk Worlds of Manchester, London, Liverpool, and Sheffield, 1975-80. Manchester: Manchester University Press.

Dabner, D., S. Calvert, and A. Casey. 2012. The New Graphic Design School: A Foundation Course in Principles and Practice. Hoboken: John Wiley \& Sons.

Emerson, S. 2007. Living Electronic Music. Hampshire: Ashgate Publishing.

Gomez-Palacio, B. and A. Wit. 2011. Graphic Design, Referenced: A Visual Guide to the Language, Applications, and History of Graphic Design. Beverly: Rockport Publishers.

Haden-Guest, A. 2015. The Last Party: Studio 54, Disco, and the Culture of the Night. New York: Open Road Integrated Media.

Holmes, T. B. and T. Holmes. 2002. Electronic and Experimental Music: Pioneers in Technology and Composition. New York: Routledge.

Holt, F. 2007. Genre in Popular Music. Chicago: University of Chicago Press.

Kosmicki, G. 2009. Musiques Electronics: Des Avant-Gardes aux Dance Floors (Electronic Music: Avant-Gardes to the Dance Floors). Marseille: Mot et le Reste.

Miller, J. 2009. Stripped: Depeche Mode. London: Onmibus Press.

Ray, M. ed. 2013. Disco, Punk, New Wave, Heavy Metal, and More: Music in the 1970s and 1980s. New York: Britannica Educational Publishing.

Reed, S. A. 2013. Assimilate: A Critical History of Industrial Music. New York: Oxford University Press.

Shaughnessy, A. 2005. How to Be a Graphic Designer, Without Losing Your Soul. London: Laurence King Publishing.

Star, E. 2009. The Everything Rock Drums Book With CD: From Basic Rock Beats and Syncopation to Fills and Drum Solos. Avon: Everything Books. 
Steyn, J. 2012. Structuring Music Through Markup Language: Design and Architectures. Hershey: IGI Global.

The Wikipedians. 2010. Alternative Rock: The Complete Guide. Mainz: Pedia Press.

Waksman, S. 2001. Instruments of Desire: The Electric Guitar and the Shaping of Musical Experience. Cambridge: Harvard University Press.

\section{Bio}

Cinla Seker, Ph.D., assistant professor, Buca Faculty of Education, Department of Fine Arts Education, Dokuz Eylul University, Turkey; research fields: graphic design, album cover design, design elements and principles, graphic design education, fine arts, art history. 